\title{
SYNTHESIS OF THIOSULPHOESTERS WITH NITROGEN CONTAINING FRAGMENTS
}

\author{
Stadnytska N. Ye., Monka N. Ya., Lubenets V. I.
}

\section{INTRODUCTION}

Modern chemistry of heterocyclic compounds is one of the most promising areas of chemical science. The heterocyclic pyrimidine system is the basic structure of many natural physiologically active substances, in particular, purine alkaloids, nucleic acids, DNA, RNA and others. The quinoline moiety is the basis of the quinine alkaloid, which has been isolated from the bark of quinine and exhibits antibacterial, antipyretic, antimalarial, analgesic and anti-inflammatory activity.

The design and synthesis of new biologically active substances containing pharmacophores of different heterocyclic nature in combination with other pharmacologically active fragments is of a particular interest in organic chemistry. Pyrimidine and quinoline structures are important nitrogen-containing heterocyclic systems used as structural blocks that are part of structures of various pharmaceuticals for the treatment and prevention of infectious diseases (fig. 1).

The cause of many infectious pathologies, in particular nosocomial infections are bacteria, especially gram-negative agents: Escherichia coli, Klebsiella spp., Enterobacter spp.; Pseudomonas aeruginosa and Acinetobacter spp. The pathogens of nosocomial infections are characterized by progressive resistance to antibacterial drugs. The results of studies of new derivatives of nitrogen-containing compounds with the pyrimidine moiety indicate the prospect of studying their properties in order to create effective antimicrobial agents for the prevention and treatment of infectious complications caused by these microorganisms ${ }^{1}$.

${ }^{1}$ Shcherbak O.M., Andreieva I.D., Kazmirchuk V.V., Rusak P.S., Menkus O.V. Perspektyvy Zastosuvannia Novykh Pokhidnykh Pirymidynu Pry Nozokomialnykh Infektsiiakh Vyklykanykh Hramnehatyvnymy Mikroorhanizmamy. Ukrainian journal of surgery. 2012. № 3 (18). P. 34-37. 
Pyrimidine derivatives have also been shown to be active against grams of bacteria and fungi of the genus Candida ${ }^{2}$.

Infectious diseases, besides bacteria and fungi, can be the representatives of the protozoa. In particular, agents of African human trypanosomosis (sleep sickness), Chagas disease and leishmaniasis are representatives of the parasitic protozoa Trypanosoma brucei, Trypanosoma cruzi and Leishmania species. Quinoline derivatives were tested for T. brucei, T. cruzi and L. infantum ${ }^{3}$, and their cytotoxic activity were demonstrated to be effective against these pathogens.
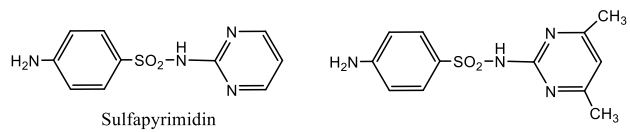

Sulphadimethylpyrimidine<smiles>O=[N+]([O-])c1ccc(O)c2ncccc12</smiles>

Nitroxoline<smiles>Cc1ccc2c(Cl)cc(Cl)c(O)c2n1</smiles>

Chlorquinaldol<smiles>COC(=O)C1CN(C(C(=O)OC)c2ccccc2F)CCC1SS(=O)(=O)c1ccc(C)cc1</smiles><smiles>CN(CC(Br)(Br)CSS(=O)(=O)c1ccccc1)C(=O)c1ccccc1</smiles><smiles>O=S(=O)(O)c1ccc2cccc(O)c2n1</smiles><smiles></smiles>

Quinzole

\section{Figure 1}

\footnotetext{
${ }^{2}$ Shcherbak O.M. Perspektyvy Vyvchennia Protymikrobnoi Dii Novykh Pokhidnykh 4N-Pirydo4'3'56pirano-23-Dpirymidynu. Aktualni Pytannia Farmatsevtychnoi I Medychnoi Nauky Ta Praktyky. 2011. № 2 (24). P. 116-118.

${ }^{3}$ Pietro O.D., Vicente-García E., Taylor M.C., Berenguer D., Viayna E., Lanzoni A., Sola I., Sayago H., Riera C., Fisa R., Clos M.V., Pérez B., Kelly J.M., Lavilla R., MuñozTorrero D. Multicomponent reaction-based synthesis and biological evaluation of tricyclic heterofusedquinolines with multi-trypanosomatid activity. European Journal of Medicinal Chemistry. 2015. № 105. P. 120-137. URL: https://doi.org/10.1016/j.ejmech.2015.10.007.
} 
Thiosulphonates $\left(\mathrm{R}_{1} \mathrm{SO}_{2} \mathrm{SR}_{2}\right)$ is a special class of disulfur-containing compounds in which one sulfur atom is hexavalent in the sulfonyl moiety $\left(-\mathrm{R}_{1} \mathrm{SO}_{2}\right)$ and divalent sulfur in the sulfide moiety $\left(-\mathrm{SR}_{2}\right)$.

Interest in thiosulphonic esters has increased significantly over the last two decades, indicating an increase in the number of publications on these compounds ${ }^{4}$. Thiosulfonic acid esters exhibit a wide range of biological effects and are proposed for use as biologically active substances for medicine, agriculture and various industries as antimicrobial agents ${ }^{5}$.

\title{
1. Synthesis of thiosulphoesters
}

\begin{abstract}
${ }^{4}$ Mampuys P., McElroy C.R., Clark J.H., Orru R.V.A., Maes B.U.W. Thiosulfonates as Emerging Reactants: Synthesis and Applications Adv. Synth. Catal. 2020. № 362. P. 3-64. URL: https://doi.org/10.1002/adsc.201901597.

${ }^{5}$ Lubenets V., Stadnytska N., Baranovych D., Vasylyuk S., Karpenko O., Havryliak V., Novikov V. Thiosulfonates: The Prospective Substances against Fungal Infections. Fungal Infection / eds. Érico Silva de Loreto and Juliana Simoni Moraes Tondolo. IntechOpen, London, 2019. DOI: 10.5772/intechopen.84436; Pylypets A.Z., Iskra R.Y., Havryliak V.V., Nakonechna A.V., Novikov V.P., Lubenets V.I. Effects of thiosulfonates on the lipid composition of rat tissues. Украӥнський біохімічний журнал. 2017. № 89. 6. P. 58-64. doi: https://doi.org/10.15407/ubj89.06.056; Oriabinska L.B., Starovoitova S.O., Vasylyuk S.V., Novikov V.P., Lubenets V.I. Ethylthiosulfanilate effect on Candida tropicalis. Украӥнський біохімічний журнал. 2017. Vol. 89. № 5. P. 70-76. doi: https://doi.org/10.15407/ubj89.05.070; Halenova T.I., Nikolaeva I.V., Nakonechna A.V., Bolibrukh K.B., Monka N.Y., Lubenets V.I., Savchuk O.M., Novikov V.P., Ostapchenko L.I. The search of compounds with antiaggregation activity among S-esters of thiosulfonic acids. Ukr. Biochem. J. 2015. № 87. 5. P. 83-92. doi: https://doi.org/10.15407/ ubj87.05.083; Lubenets V.I., Stadnitskaya N.Ye., Novikov V.P. Synthesis of thiosulfonates belonging to quinoline derivatives. Russ. J. Org. Chem. 2000. № 36. P. 851-853. DOI: https://doi.org/10.1007/BF02757443; Sato, R., Akutsu, Y., Goto, T., Saito, M. Benzopentathiepin as sulfurization reagent. Novel synthesis of thiosulfonates from sulfinates. Chem. Lett. 1987. № 16. P. 2161-2162; Baranovich D.B., Lubenets V.I., Novikov V.P. Synthesis of thiosulfonates with functional groups in the aliphatic chain. Russ. J. Org. Chem. 2001. № 37. P. 1046-1047; Baranovich D.B., Lubenets V.I., Novikov V.P. Synthesis of S-[2-(4-Aminobenzenesulfonyl)ethyl] and S-[2-(3-Amino-4methoxybenzenesulfonyl)ethyl] Thiosulfonates. Russ. J. Gen. Chem. 2001. № 71. P. 1827-1827. DOI: https://doi.org/10.1023/A:1013987618313; Zhao Q., Lu L., Direct Q. Monofluoromethylthiolation with S-(Fluoromethyl) Benzenesulfonothioate. Shen, Angew. Chem. 2017. № 129. P. 11733-11736; Angew. Chem. Int. Ed. 2017. № 56. P. 1157511578. DOI: 10.1002/anie.201705633; Lubenets V.I., Vasylyuk S.V., Novikov V.P. Synthesis of S-(3-chloroquinoxalin-2-yl) esters of aliphatic and aromatic thiosulfonic acids. Chem. Heterocycl. Compd. 2005. № 41. P. 1547-1548. DOI: https://doi.org/10.1007/s10593-006-0039-9; Chura B., Lubenets V.I., Goi O.V., Novikov V.P. The Reaction of Sodium 4-Acetylaminobenzenethiosulfonate with 2,3Dichloroquinoxaline. Chem. Heterocycl. Compd. 2002. № 38. P. 1432-1433. DOI: 10.1023/A:1022163417299; Lubenets V.I., Vasylyuk S.V., Goi O.V., Novikov V.P. Reaction of 6,7-dichloroquinoline-5,8-quinone with thiosulfonic acid salts. Chem. Heterocycl. Compd. 2006. № 42. P. 961-962. DOI: https://doi.org/10.1007/s10593-0060189-9.
\end{abstract}


Given the high synthetic and pharmacological potential of thiosulphonic acid derivatives, which are potent electrophilic sulfonylating and nucleophilic thiolating reagents, it is very important to design systems that would contain various combinations of thiosulphonylacetamines. These structures are likely to exhibit new or modified biological activity. The presented study demonstrates the predicted preferential directions of experimental studies of the biological activity of thiosulfonic acid esters with pyrimidine and quinoline fragments in the composition of their molecules and their practical application. To achieve this goal, the design of thiosulfonate structures with nitrogen-containing heterocyclic fragments has been performed, which is presented below.

We have investigated possible ways of obtaining thiosulphoesters with pyrimidine moieties.

One of which can be represented by a number of transformations:

$$
\mathrm{RSO}_{2} \mathrm{Cl} \stackrel{\mathrm{Na}_{2} \mathrm{~S}, \mathrm{KHS}}{\longrightarrow} \mathrm{RSO}_{2} \mathrm{SNa}(\mathrm{K}) \stackrel{\mathrm{AlkBr}}{\longrightarrow} \mathrm{RSO}_{2} \mathrm{SAlk}
$$

Pyrimidine derivatives with $\mathrm{OH}-$ and $\mathrm{NH}_{2}$ - groups are known to be the most sulfonated, but such sulfochlorides are unknown. 2-amino-6-methylpyrimidin-4ol 1 and dibromohydrate 5-bromomethyl-2-methylpyrimidine-4-amine 7 were selected as the objects of our studies. The intermediate product for the synthesis of thiosulphoesters is the corresponding sulfochloride, so we investigated the chlorosulfonation of 2- amino-6-methylpyrimidin-4-ol 1 five times the excess chlorosulfonic acid at a temperature of $0-5^{\circ} \mathrm{C}$, followed by heating the sulfomass to $110-125^{\circ} \mathrm{C}$ according to fig. 2 .

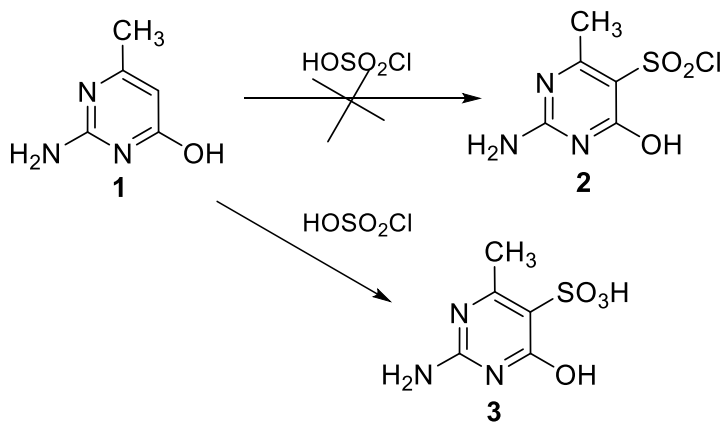

Figure 2 
It was not possible to obtain sulfochloride $\mathbf{2}$ directly under the above conditions. Instead, in $80 \%$ yield sulfonic acid $\mathbf{3}$ was obtained, which was subsequently used to obtain the target sulfochloride $\mathbf{2}$. Compound $\mathbf{2}$ was obtained by boiling salt $\mathbf{4}$, which was previously converted to 2-amino-4hydroxy-6-methylpyrimidine-5-sulfonic acid 3 with excess thionyl chloride.

To obtain the corresponding thiosulfonate 5a,b sulfochloride $\mathbf{2}$ was used without further purification.

Attempts to obtain the sodium and potassium salts of 2-amino-4hydroxy-6-methyl-pyrimidine-5-thiosulfonic acid 5a, b were not successful. Because compound $\mathbf{2}$ is weak and rapidly hydrolyzes, interaction with sodium sulfide or potassium hydrosulfide results in the formation of sodium or potassium sulfonates $\mathbf{6 a}, \mathbf{b}$ instead of the target thiosulfonates $\mathbf{5 a}, \mathbf{b}$.

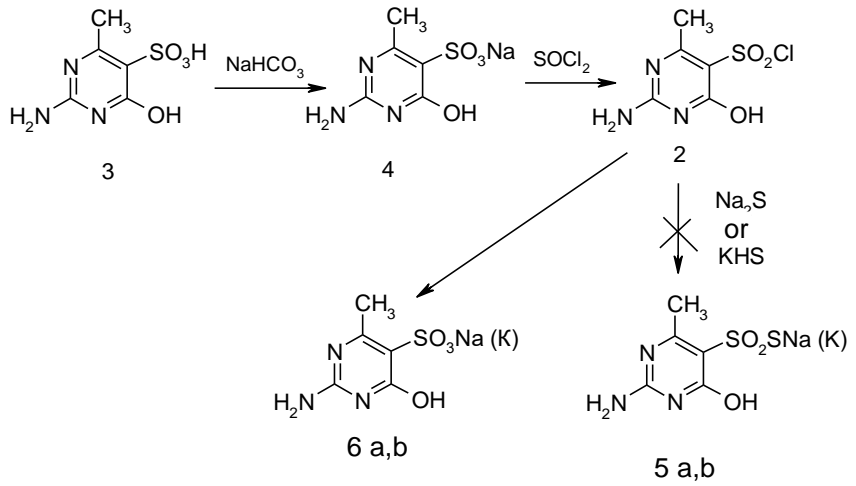

Figure 3

The dibromohydrate of 5-bromomethyl-2-methylpyrimidine-4-amine is an intermediate in the production of vitamin $B_{1}$ (thiamine). An additional argument when choosing this feedstock was that its pyrimidine moiety is included in the structure of the anticancer drug Nimustine ${ }^{6}$.

The replacement of bromine by the sulfo group in the dibromohydrate of 5-bromomethyl-2-methylpyrimidin-4-amine $\mathbf{7}$ was carried out with prolonged boiling of compound 7 with saturated sodium sulfite solution.

${ }^{6}$ Mashkovskiy M.D. Lekarstvennyie sredstva. 16-e izdanie, pererab. i dopoln. Moskva : Novaya volna izdatel Umerenkov, 2010. 1216 p. 


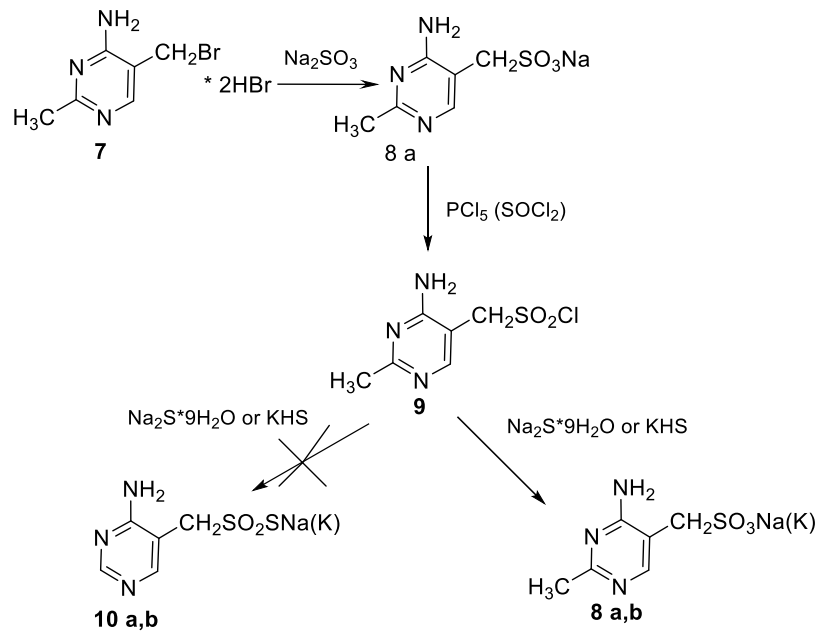

Figure 4

Phosphorus pentachloride or thionyl chloride was used to obtain the corresponding sulfochloride $\mathbf{9}$ from sodium sulfonate $\mathbf{8 a}$.

Chlorohydride 9 is an unstable compound that hydrolyzes rapidly. The study of the redox interaction of sulfochloride 9 with potassium hydrosulfide or sodium sulfide found that instead of the predicted thiosulfonates $\mathbf{1 0}$ a,b sodium or potassium sulfonates $\mathbf{8} \mathbf{a}, \mathbf{b}$ were obtained.

Thus, this way of synthesis of thiosulfonic acid esters of pyrimidine derivatives did not produce the expected results, since the investigated sulfochlorides are not heat-resistant at room temperature which makes it difficult to obtain the corresponding salts of thiosulfonic acids from them.

As an alternative method of obtaining thiosulfoesters with a pyrimidine moiety, we investigated the possibility of using 5-bromomethyl-2methylpyrimidine-4-amine 7 dibromohydrate as an alkylating reagent. The original dibromohydrate was converted to compound $\mathbf{1 1}$ and was reacted with potassium or sodium salts of different thiosulfonic acids in acetoneaqueous medium at room temperature for 7-10 days. Solid crystalline thiosulphoesters 12 a-d were obtained in $29-57 \%$ yields, which were soluble in acetone, alcohol and partially in water. 
<smiles></smiles>

7

11

$12 \mathrm{a}-\mathrm{d}$

$\mathrm{R}=\mathrm{C}_{6} \mathrm{H}_{5}(\mathrm{a}), 4-\mathrm{ClC}_{6} \mathrm{H}_{4}(\mathrm{~b}), 4-\mathrm{NH}_{2} \mathrm{C}_{6} \mathrm{H}_{4}(\mathrm{c}), 4-\mathrm{CH}_{3} \mathrm{COONHC}_{6} \mathrm{H}_{4}(\mathrm{~d})$

Figure 5

Physicochemical characteristics of the obtained thiosulphoesters 12 a-d:

Benzenethiosulfonic acid 4-amino-2-methylpyrimidin-5-yl-methyl ester 12a Yield $28 \%$, mp: $163-164^{\circ} \mathrm{C},{ }^{1} \mathrm{HNMR}\left(300 \mathrm{MHz}, \mathrm{CDCl}_{3}\right) \delta$, pmm: 2,32 (3H, s, $\left.\mathrm{CH}_{3}\right), 4,26$ (2H, s , S- $\left.\mathrm{CH}_{2}\right), 6,40$ (2H, br.s $\left.\mathrm{NH}_{2}\right), 7,54-8,06$ (м. 5H, 5Ar-H), 8,92 (1H, s, CH=N); IR (KBr, cm-1): 3446, $3398\left(\mathrm{NH}_{2}\right), 1600$, 1596 (Ar); 1582, 1488, 1464, (pyrimid. cycle); 1326 $6_{\text {as, }} 1124_{\gamma \mathrm{s}},\left(\mathrm{SO}_{2}\right)$; Anal.calcd for $\mathrm{C}_{12} \mathrm{H}_{13} \mathrm{~N}_{3} \mathrm{O}_{2} \mathrm{~S}_{2}$ : C 48,46 H 4,38 N 14,13 S 21,89; found: C 48,28 H 4,28 N 14,12 S 21,81;

4-Chlorobenzenethiosulfonic acid 4-amino-2-methylpyrimidin-5-ylmethyl ester12 b Yield 52\%, mp: $110-112^{\circ} \mathrm{C}$, 1HNMR (300 MHz, CDCl3) $\delta$, pmm: 2.36 (3H, s, CH3 ), 4.34 (2H, s , S-CH2), 6.36 (2H, s, NH2), 7,38$8,0(4 \mathrm{H}, \mathrm{m}, 4 \mathrm{Ar}-\mathrm{H}), 8.90(1 \mathrm{H}, \mathrm{s}, \mathrm{CH}=\mathrm{N})$; IR $(\mathrm{KBr}, \mathrm{cm}-1): 3466,3380$

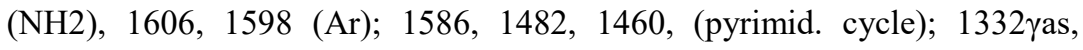
1144 $\gamma$ s, (SO2); Anal.calcd for $\mathrm{C}_{12} \mathrm{H}_{12} \mathrm{ClN}_{3} \mathrm{O}_{2} \mathrm{~S}_{2} \mathrm{C} 43,08 \mathrm{H} \mathrm{4,23} \mathrm{N} \mathrm{12,64} \mathrm{S}$ 19,39; found: C 43,04 H 4,20 N 12,65 S 19,07;

4-Aminobenziothiosulfonic acid 4-amino-2-methylpyrimidin-5yl-methyl ester 12 c Yield 56\%, mp: $202-203^{\circ} \mathrm{C},{ }^{1} \mathrm{HNMR}(300 \mathrm{MHz}$, $\left.\mathrm{CDCl}_{3}\right) \delta$, pmm: $2.48\left(3 \mathrm{H}, \mathrm{s}, \mathrm{CH}_{3}\right), 4.38\left(2 \mathrm{H}, \mathrm{s}, \mathrm{S}-\mathrm{CH}_{2}\right), 6,46\left(2 \mathrm{H}, \mathrm{s}, \mathrm{NH}_{2}\right)$, 6,48 (2H, s, $\left.2 \mathrm{NH}_{2}\right), 7,4-8,1(4 \mathrm{H}, \mathrm{m}, 4 \mathrm{Ar}-\mathrm{H}), 8.94(1 \mathrm{H}, \mathrm{s}, \mathrm{CH}=\mathrm{N})$; IR (KBr, cm-1): 3536, 3502, 3466, $3380\left(\mathrm{NH}_{2}\right), 1600,1596$ (Ar); 1586, 1482, 1460, (pyrimid. cycle); $1332_{\gamma \text { as, }} 1144_{\gamma \mathrm{s}},\left(\mathrm{SO}_{2}\right)$; Anal.calcd for $\mathrm{C}_{12} \mathrm{H}_{14} \mathrm{~N}_{4} \mathrm{O}_{2} \mathrm{~S}_{2}$. C 46,68 H 4,32 N 18,11 S 20,41 found: C 46,70 H 4,28 N 18,03S 20,09;

4-[(methoxycarbonyl)amino] benzenethiosulfonic acids 4-amino-2methylpyrimidin-5-yl-methyl ester12 d Yield $30 \%, \mathrm{mp}: 172-173^{\circ} \mathrm{C}$, 1HNMR (300 MHz, CDCl3) $\delta$, pmm: 2.32 (3H, s, CH3), 2.64 (3H, s, CH3), 4.24 (2 H, s, S-CH2), 6.62 (2H, s, 2 NH2), 7.76 (2H, д, J=8, CH); $7.92(2 \mathrm{H}$, д, J=8, CH); $8.11(1 \mathrm{H}, \mathrm{s}, \mathrm{CH}=\mathrm{N}) 10.08(1 \mathrm{H}, \mathrm{c}, \mathrm{NH})$; IR (KBr, cm-1): 3440, $3400(\mathrm{NH} 2), 3326(\mathrm{NH})$; 1632, $(\mathrm{C}=\mathrm{O})$; $1602(\mathrm{Ar}) ; 1580,1540,1452$, 


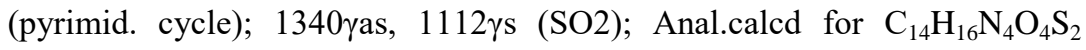
C 45,65 H 4,38 N 15,21 S 17,39; found: C 45,79 H 4,20 N 15,24 S 17,12.

For the synthesis of thiosulphoesters 18 a-g with heterocyclic nitrogencontaining moiety we have chosen quinoline $\mathbf{1 4}$ and 8-quinolinesulfonic acid $\mathbf{1 3 .}$

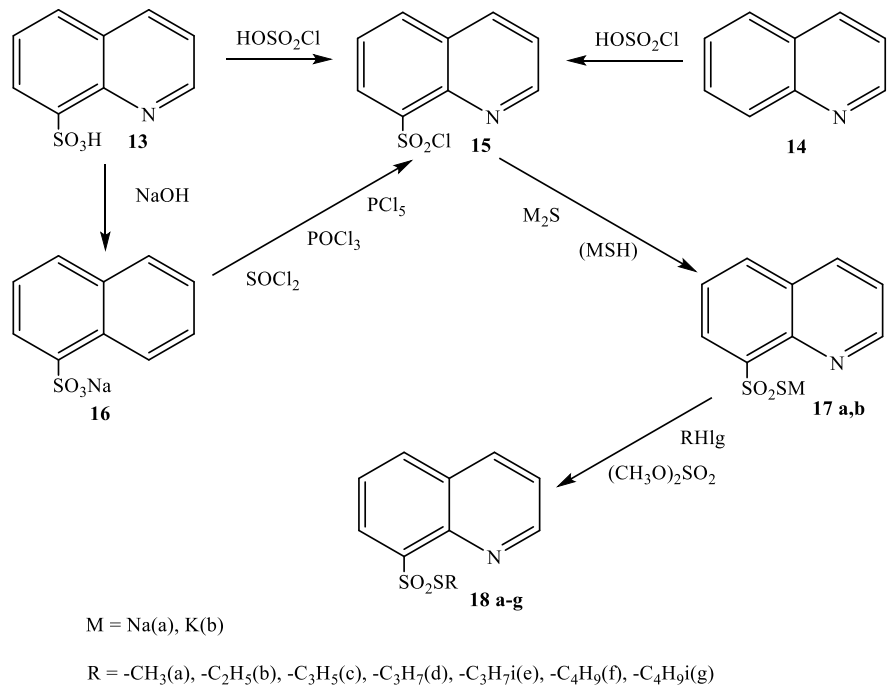

Figure 6

Quinoline and 8-quinolinesulfonic acid were obtained from 8-quinoline sulphochloride $\mathbf{1 5}$, which was subsequently converted to the alkali metal salts of 8-quinolinethiosulfonic acids $\mathbf{1 7} \mathbf{a , b}$.

The redox interaction of the synthesized 8-quinolinesulfochloride 15 with an aqueous solution of sodium sulfide to obtain the sodium salt of 8-quinolintiosulfonic acid $\mathbf{1 7}$ a has been investigated. This process takes place in two stages. 


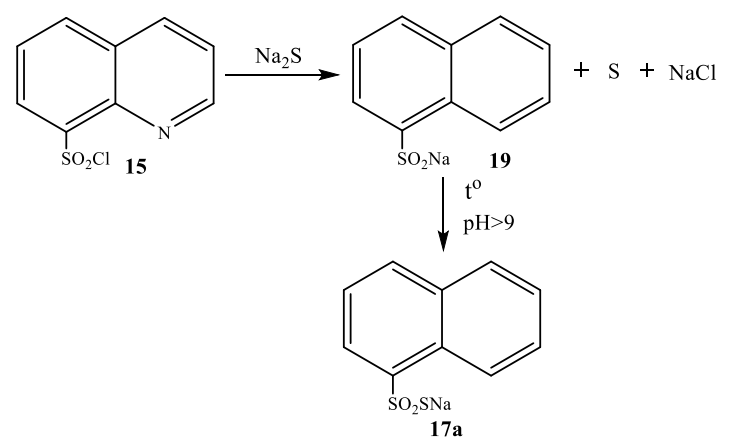

Figure 7

In the first stage, the sulfochloride is reduced to sulfinate with the release of elemental sulfur, which when heated react with each other to form the sodium salt of 8-quinoline thiosulfonic acid (the second stage of interaction). Upon cooling the reaction mass, the final product crystallizes and precipitates. The filtered salt was purified by recrystallization from ethanol. The 8-quinoline thiosulfonic acid potassium salt was prepared analogously to the sodium salt by replacing sodium sulfide with a saturated potassium hydrosulfide solution.

Alkylation of the sodium or potassium salts of 8-quinolinethiosulfonic acids by various alkyl halides or dialkyl sulfates in acetone-water or alcohol media synthesizes the corresponding S-alkyl- (8-quinoline) thiosulfonates.

We also conduct synthesis to produce thiosulphoesters containing an 8-hydroxyquinoline moiety.

The purity and individuality of the samples with quinoline fragments 18 a-g and 25 a-c are attested by the TLC method. The structure and composition of the synthesized thiosulphoesters were confirmed by IR, ${ }^{1} \mathrm{H}$ NMR spectroscopy, elemental analysis which is provided below: 


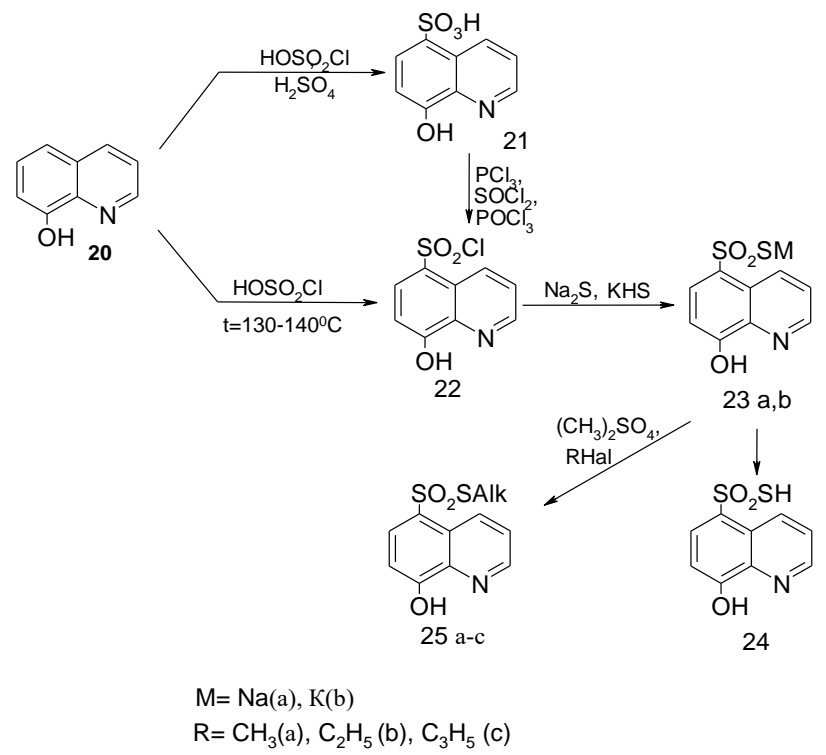

Figure 8

S-Methyl-8-quinoline thiosulphonate 18 a Yield $50 \%, \mathrm{mp}: 120^{\circ} \mathrm{C}$, 1HNMR (300 MHz, CDCl3) $\delta$, pmm: 1.74 с $(3 \mathrm{H}, \mathrm{SCH} 3), 7.68-7.82$ м $(3 \mathrm{H}$, Ar-H), 7.68-9.15 м (6H, Ar-H); IR (KBr, cm-1): 1306, 1132 (SO2); 832, 788, 764 (quinoline nucleus); Anal.calcd for $\mathrm{C}_{10} \mathrm{H}_{9} \mathrm{NO}_{2} \mathrm{~S}_{2} \mathrm{C} 50.19 \mathrm{H} 3.79 \mathrm{~N}$ 5.85 S 26.79; found: C $50.00 \mathrm{H} 4.03$ N 5.77 S 26.61;

S-Ethyl-8-quinoline thiosulphonate 18 b Yield $42 \%, \mathrm{mp}: 77{ }^{\circ} \mathrm{C}$, ${ }^{1} \mathrm{HNMR}\left(300 \mathrm{MHz}, \mathrm{CDCl}_{3}\right) \delta$, pmm: 1.23 т $\left(3 \mathrm{H}, \mathrm{CH}_{3}\right), 3.30$ к $\left(2 \mathrm{H}, \mathrm{SCH}_{2}\right)$, 7.76-7.88 м (3H, Ar-H), 7.76-9.16 м (6H, Ar-H); IR $\left(\mathrm{KBr}, \mathrm{cm}^{-1}\right)$ : 1308, 1136, $1124\left(\mathrm{SO}_{2}\right) ; 828,784,760$ (quinoline nucleus); Anal.calcd for $\mathrm{C}_{11} \mathrm{H}_{11} \mathrm{NO}_{2} \mathrm{~S}_{2} \mathrm{C} 52.15 \mathrm{H} 4.38 \mathrm{~N} 5.53 \mathrm{~S} 25.31$; found: C $52.41 \mathrm{H} 4.63 \mathrm{~N}$ $5.57 \mathrm{~S} 25.51$;

S-Allyl-8-quinoline thiosulphonate 18 c Yield $42 \%, \mathrm{mp}: 58-60^{\circ} \mathrm{C}$, ${ }^{1} \mathrm{HNMR}\left(300 \mathrm{MHz}, \mathrm{CDCl}_{3}\right) \delta, \mathrm{pmm}: 4.02$ д $\left(2 \mathrm{H}, \mathrm{SCH}_{2}\right), 4.98-5.88$ м $\left(2 \mathrm{H},=\mathrm{CH}_{2}\right), 5.52-5.86$ м $(\mathrm{H},-\mathrm{CH}=), 7.70-9.20$ м $(6 \mathrm{H}, \mathrm{Ar}-\mathrm{H}), 7.70-7.90$ м $(3 \mathrm{H}, \mathrm{Ar}-\mathrm{H})$; IR $\left(\mathrm{KBr}, \mathrm{cm}^{-1}\right): 1640\left(\mathrm{CH}=\mathrm{CH}_{2}\right), 1320,1160,1124\left(\mathrm{SO}_{2}\right) ; 832$, 792, 772 (quinoline nucleus); Anal.calcd for $\mathrm{Cl}_{2} \mathrm{H}_{11} \mathrm{NO}_{2} \mathrm{~S}_{2} \mathrm{C} 54.32 \mathrm{H} 4.18 \mathrm{~N}$ 5.28 S 24.16; found: C 54.43 H 4.37 N 5.36 S 24.24; 
S-Propyl-8-quinoline thiosulphonate 18 d Yield $60 \%, \mathrm{mp}: 55^{\circ} \mathrm{C}$, ${ }^{1} \mathrm{HNMR}\left(300 \mathrm{MHz}, \mathrm{CDCl}_{3}\right) \delta$, pmm: 0.99 т $\left(3 \mathrm{H}, \mathrm{CH}_{3}\right), 1.75$ м $\left(2 \mathrm{H}, \mathrm{CH}_{2}\right)$, 2.85 м (2H, $\left.\mathrm{SCH}_{2}\right), 7.69-8.14$ м (3H, Ar-H), 7.69-9.17 м (6H, Ar-H); IR $\left(\mathrm{KBr}, \mathrm{cm}^{-1}\right)$ : 1326, 1116, $\left(\mathrm{SO}_{2}\right) ; 830,786,764$ (quinoline nucleus); Anal.calcd for $\mathrm{C}_{12} \mathrm{H}_{13} \mathrm{NO}_{2} \mathrm{~S}_{2} \mathrm{C} 53.91 \mathrm{H} 4.90 \mathrm{~N} 5.24 \mathrm{~S} 23.98$; found: C 53.90 H 5.18 N 5.19 S 24.18;

S-Iso-propyl-8-quinoline thiosulphonate 18 e Yield $17 \%$, mp: $150^{\circ} \mathrm{C}$, 1HNMR (300 MHz, CDCl3) $\delta$, pmm: 1.48 д (3H,CH3), 2.96 м (6H, $\mathrm{SCH}(\mathrm{CH} 3) 2,6.95-7.73$ м (3H, Ar-H), 6.95-9.16 м (6H, Ar-H); IR (KBr, $\mathrm{cm}^{-1}$ ): 1332, 1112 (SO2); 836, 790, 758 (quinoline nucleus); Anal.calcd for $\mathrm{C}_{12} \mathrm{H}_{13} \mathrm{NO}_{2} \mathrm{~S}_{2} \mathrm{C} 53.91 \mathrm{H} 4.90 \mathrm{~N} 5.24 \mathrm{~S} 23.98$; found: C $53.73 \mathrm{H} 5.12 \mathrm{~N} 5.20$ S 23.96;

S-Butyl-8-quinoline thiosulphonate 18 f Yield $70 \%, \mathrm{mp}: 65^{\circ} \mathrm{C}$, 1HNMR (300 MHz, CDCl3) $\delta$, pmm: 0.94 т (3H,CH3), 1.58 м (2H, CH2), 1.62 м (2H, CH2), 2.95 м (2H, SCH2), 7.75-8.81 м (3H, Ar-H), 7.75-9.17 м (6H, Ar-H); IR (KBr, cm-1): 1340, 1116 (SO2); 886, 830, 762 (quinoline nucleus); Anal.calcd for $\mathrm{C}_{13} \mathrm{H}_{15} \mathrm{NO}_{2} \mathrm{~S}_{2} \mathrm{C} 55.49 \mathrm{H} 5.37 \mathrm{~N} 4.98 \mathrm{~S} 22.79$; found: C 55.62 H 5.65 N 4.94 S 22.63;

S-Iso-butyl-8-quinoline thiosulphonate 18 g Yield $24 \%, \mathrm{mp}: 160^{\circ} \mathrm{C}$, ${ }^{1} \mathrm{HNMR}\left(300 \mathrm{MHz}, \mathrm{CDCl}_{3}\right) \delta$, pmm: $0.96 \mathrm{c}\left(3 \mathrm{H}, \mathrm{CH}_{3}\right), 0.98 \mathrm{c}\left(3 \mathrm{H}, \mathrm{CH}_{3}\right), 2.00$ м (H, CH), 278 д (2H, $\left.\mathrm{SCH}_{2}\right), 7.73-8.24$ м (3H, Ar-H), 7.73-9.16 м (6H, $\mathrm{Ar}-\mathrm{H})$; IR (KBr, cm $\left.{ }^{-1}\right)$ : 1308, $1126\left(\mathrm{SO}_{2}\right)$; 832, 790, 766 (quinoline nucleus); Anal.calcd for $\mathrm{C}_{13} \mathrm{H}_{15} \mathrm{NO}_{2} \mathrm{~S}_{2} \mathrm{C} 55.49 \mathrm{H} 5.37 \mathrm{~N} 4.98 \mathrm{~S} 22.79$; found: C 55.72 H 5.50 N 4.90 S 22.70;

S-Methyl-8-hydroxyquinoline thiosulphonate 25 a Yield 62\%, mp: $72-73^{\circ} \mathrm{C}$; IR $\left(\mathrm{KBr}, \mathrm{cm}^{-1}\right)$ : $3600(\mathrm{OH})$; 1340, $1136\left(\mathrm{SO}_{2}\right)$; Anal.calcd for $\mathrm{C}_{10} \mathrm{H}_{9} \mathrm{NO}_{3} \mathrm{~S}_{2} \mathrm{C} 47.05 \mathrm{H} 3.55 \mathrm{~N} 5.49 \mathrm{~S} 3.94$; found: C $46.82 \mathrm{H} 3.83 \mathrm{~N} 5.31 \mathrm{~S}$ 24.93;

S-Ethyl-8-hydroxyquinoline thiosulphonate 25 b Yield 41\%, mp: $121^{\circ} \mathrm{C}$; IR $\left(\mathrm{KBr}, \mathrm{cm}^{-1}\right): 3605(\mathrm{OH})$; 1330, $1124\left(\mathrm{SO}_{2}\right)$; Anal.calcd for $\mathrm{C}_{11} \mathrm{H}_{11} \mathrm{NO}_{3} \mathrm{~S}_{2} \mathrm{C} 49.06 \mathrm{H} 4.12 \mathrm{~N} 5.20 \mathrm{~S} \mathrm{33.80}$; found: C $48.85 \mathrm{H} 4.35 \mathrm{~N} 5.06$ S 23.62;

S-Allyl-8- hydroxyquinoline thiosulphonate 25 c Yield 56\%, mp: $37^{\circ} \mathrm{C}$; IR $\left(\mathrm{KBr}, \mathrm{cm}^{-1}\right): 3600(\mathrm{OH}) ; 1620\left(\mathrm{CH}=\mathrm{CH}_{2}\right), 1320,1112\left(\mathrm{SO}_{2}\right)$; Anal.calcd for $\mathrm{C}_{12} \mathrm{H}_{11} \mathrm{NO}_{3} \mathrm{~S}_{2} \mathrm{C} 51.23 \mathrm{H} 3.94 \mathrm{~N} 4.98 \mathrm{~S} 22.79$; found: $\mathrm{C} 51.06$ H 4.23 N 4.76 S $22.63 ю$ 


\section{Predicted activity}

Computer-aided biological screening for Prediction of Activity Spectra for Substances (PASS) was performed for the above compounds. The principle of operation of this program is based on the analysis of the dependence "structure-activity" for substances in the training sample, which contains more than 80,000 different biologically active substances (substances of known drugs and physiologically active compounds), the data of which are constantly updated with new results of biological activity of compounds published in the scientific and technical literature and numerous databases, as well as with information from unpublished documents ${ }^{7}$.

A particularly promising trend in studies of the biological activity of substances is to increase the physiological effect of drugs. Therefore, data on the full spectrum of biological action of known and first synthesized potential biologically active compounds, the identification of certain types of biological activity of substances and the correlation between structure and biological action can be the basis for their practical use, in particular as medicinal substances. Advanced screening of biological activity can determine the direction of further experimental studies of synthesis compounds without significant time and cost.

The average forecast accuracy of the PASS program is about $85 \%$, which is sufficient to use the data obtained to predict the spectrum of biological activity of new substances (the expected average prediction accuracy of one of the 500 types of activity is only about $0.2 \%)^{8}$. The results of the forecast provide information on the list of likely activities and the estimated probability of (Ra) presence and ( $\mathrm{Ri}$ ) absence of each activity. The numerical estimates of the probabilities of $\mathrm{Ra}$ and $\mathrm{Ri}$ are in the range from 0 to 1 , and their sum is usually not equal to one, since the probabilities of the presence and absence of a certain type of physiological activity are calculated independently. The results of the screening are shown in Tables 1-3.

7 Gloriozova A., Filimonov D.A., Lagunin A.A., Poroykov V.V. Testirovanie kompyuternoy sistemyi dlya predskazaniya biologicheskoy aktivnosti PASS na vyibor kenovyih himicheskih soedineniy. Him.-farm. zhurnal. 1998. № 32. 12. P. 32-39.

${ }^{8}$ Lagunin A., Stepanchikova A., Filimonov D., Poroikov V. PASS: prediction of activity spectra for biologically active substances. Bioinformatics. 2000. № 16.8. P. 747-748. 
The predicted effect of the biological action of 4-amino-2-methylpyrimidin-5-yl-methyl thiosulfonic acid esters 12 a-d according to PASS program

\begin{tabular}{|c|c|c|c|c|}
\hline \multirow{2}{*}{ Activity } & \multicolumn{4}{|c|}{ Number of the compound } \\
\hline & $\mathrm{C}_{6} \mathrm{H}_{5}$ & $4-\mathrm{ClC}_{6} \mathrm{H}_{4}$ & $4-\mathrm{NH}_{2} \mathrm{C}_{6} \mathrm{H}_{4}$ & 4- $\mathrm{CH}_{3} \mathrm{COONHC}_{6} \mathrm{H}_{4}$ \\
\hline $\begin{array}{c}\text { 4-Hydroxybenzoate-CoA } \\
\text { ligase inhibitor }\end{array}$ & 0.512 & 0.441 & 0.477 & - \\
\hline $\begin{array}{c}\text { Alcohol } \\
\text { O-acetyltransferase } \\
\text { inhibitor }\end{array}$ & 0.693 & 0.655 & 0.675 & 0.868 \\
\hline $\begin{array}{l}\text { Antineoplastic } \\
\text { (solid tumors) }\end{array}$ & 0.482 & 0.462 & 0.467 & 0.792 \\
\hline Antiprotozoal (Coccidial) & - & 0.397 & 0.409 & - \\
\hline $\begin{array}{c}\text { Benzoate-CoA ligase } \\
\text { inhibitor }\end{array}$ & 0.927 & 0.908 & 0.918 & 0.594 \\
\hline $\begin{array}{c}\text { Butyrate-CoA ligase } \\
\text { inhibitor }\end{array}$ & 0.641 & 0.387 & 0.487 & - \\
\hline Cathepsin T inhibitor & 0.451 & - & - & - \\
\hline Cathepsin T inhibitor & 0.451 & - & - & - \\
\hline $\begin{array}{c}\text { CDP-glycerol } \\
\text { glycerophosphotransferase } \\
\text { inhibitor } \\
\end{array}$ & - & - & - & 0,492 \\
\hline Chemoprotective & 0.84 & 0.821 & 0,825 & 0,469 \\
\hline $\begin{array}{c}\text { Glycine-tRNA ligase } \\
\text { inhibitor }\end{array}$ & 0.573 & 0.528 & 0.552 & 0.45 \\
\hline $\begin{array}{c}\text { Glycosylphosphatidylino } \\
\text { sitol phospholipase } \\
\text { D inhibitor } \\
\end{array}$ & - & 0.437 & - & - \\
\hline $\begin{array}{c}\text { Imidazoline I1 receptor } \\
\text { agonist }\end{array}$ & - & - & - & 0.335 \\
\hline Kinase inhibitor & 0,462 & 0,434 & 0,446 & - \\
\hline $\begin{array}{c}\begin{array}{c}\text { Phosphodiesterase } \\
\text { inhibitor }\end{array} \\
\end{array}$ & 0,712 & 0,588 & 0,638 & 0.403 \\
\hline $\begin{array}{c}\text { Thiamine pyridinylase } \\
\text { inhibitor }\end{array}$ & - & - & 0.447 & - \\
\hline Thioredoxin inhibitor & 0.475 & - & - & - \\
\hline Venombin $\mathrm{AB}$ inhibitor & 0.477 & - & - & - \\
\hline
\end{tabular}

According to the data obtained, the title compound is benzene thiosulfonic acid 4-amino-2-methylpyrimidin-5-yl-methyl ester. Alcohol O-acetyltransferase, Benzoate-CoA ligase, Chemoprotective Glycine-tRNA ligase, Phosphodiesterase, and Antineoplastic (solid tumors) activity have been found to inhibit the activity of all esters. 
Table 2

The predicted effect of the biological action of S-alkyl esters of 8-quinoline thiosulfonic acid 18 a-g according to PASS program

\begin{tabular}{|c|c|c|c|c|c|c|c|}
\hline \multirow[b]{2}{*}{ Activity } & \multicolumn{7}{|c|}{ Number of the compound } \\
\hline & $\overline{0}$ & $\underbrace{N}_{i}$ & $e_{1}^{\infty}$ & $e_{1}^{5}$ & $\frac{\stackrel{m}{1}}{\underbrace{m}_{1}}$ & $\underset{1}{\vec{Z}}$ & 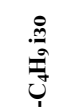 \\
\hline 1 & 2 & $\mathbf{3}$ & 4 & 5 & 6 & 7 & 8 \\
\hline $\begin{array}{l}\text { (R)-6-hydroxynicotine oxidase } \\
\text { inhibitor }\end{array}$ & 0.83 & 0.729 & 0.774 & 0.673 & 0.752 & 0.645 & 0.65 \\
\hline $\begin{array}{l}\text { (S)-3-hydroxyacid ester } \\
\text { dehydrogenase inhibitor }\end{array}$ & 0.717 & - & 0.63 & - & - & - & - \\
\hline $\begin{array}{l}\text { (S)-6-hydroxynicotine oxidase } \\
\text { inhibitor }\end{array}$ & 0.853 & 0.749 & 0.796 & 0.683 & 0.774 & 0.65 & 0.661 \\
\hline $\begin{array}{c}\text { 2-Hydroxyquinoline } \\
\text { 8-monooxygenase inhibitor }\end{array}$ & 0.758 & - & 0.643 & 0.572 & - & - & - \\
\hline $\begin{array}{l}\text { 4-Hydroxyproline epimerase } \\
\text { inhibitor }\end{array}$ & 0.728 & - & 0.566 & - & - & - & - \\
\hline $\begin{array}{c}\text { 4-Methoxybenzoate } \\
\text { monooxygenase } \\
\text { (O-demethylating) inhibitor }\end{array}$ & - & - & 0.668 & - & - & - & - \\
\hline $\begin{array}{c}\text { Aldehyde } \\
\text { dehydro-genase } \\
\text { (pyrroloquinoline-quinone) } \\
\text { inhibitor }\end{array}$ & 0.813 & - & 0.827 & - & 0.724 & - & - \\
\hline $\begin{array}{l}\text { Alkane 1-monooxygenase } \\
\text { inhibitor }\end{array}$ & 0.745 & - & 0.634 & - & 0.703 & - & 0.521 \\
\hline Antiseborrheic & - & - & - & 0.689 & - & 0.626 & 0.729 \\
\hline Antihypertensive & - & - & - & - & - & - & 0.499 \\
\hline Amine dehydrogenase inhibitor & - & - & 0.544 & - & - & - & - \\
\hline Arylacetonitrilase inhibitor & 0.818 & 0.828 & 0.594 & 0.626 & 0.71 & 0.525 & 0.626 \\
\hline Arylalkyl acylamidase inhibitor & 0.843 & 0.753 & 0.75 & 0.628 & 0.79 & 0.519 & 0.522 \\
\hline $\begin{array}{c}\text { Aspulvinone } \\
\text { dimethylallyltransferase inhibitor }\end{array}$ & - & - & 0.696 & - & - & - & - \\
\hline Benzoate-CoA ligase inhibitor & - & - & - & - & - & 0.563 & - \\
\hline Biotinidase inhibitor & - & - & - & - & - & - & 0.613 \\
\hline Bothrolysin inhibitor & 0.829 & - & 0.754 & 0.562 & 0.723 & 0.514 & 0.562 \\
\hline $\begin{array}{c}\text { Carbon-monoxide dehydrogenase } \\
\text { inhibitor }\end{array}$ & - & - & 0.572 & - & - & - & 0.5 \\
\hline Carboxypeptidase Taq inhibitor & 0.847 & 0.79 & 0.779 & 0.819 & 0.814 & 0.837 & 0.699 \\
\hline Carnitinamidase inhibitor & 0.802 & 0.761 & 0.714 & 0.732 & - & 0.696 & 0.652 \\
\hline Cathepsin T inhibitor & - & - & - & - & - & - & 0.512 \\
\hline Chemoprotective & 0.717 & - & 0.6 & - & - & 0.545 & 0.515 \\
\hline $\begin{array}{c}\text { Chenodeoxycholoyltaurine } \\
\text { hydrolase inhibitor }\end{array}$ & - & - & 0.543 & - & - & - & - \\
\hline Chloride peroxidase inhibitor & - & - & 0.623 & - & - & - & - \\
\hline $\begin{array}{c}\text { Cis-1,2-dihydro-1,2- } \\
\text { dihydroxynaphthalene } \\
\text { dehydrogenase inhibitor }\end{array}$ & - & - & 0.531 & - & - & - & - \\
\hline $\begin{array}{l}\text { Corticosteroid side-chain- } \\
\text { isomerase inhibitor }\end{array}$ & 0.719 & - & 0.557 & - & - & - & - \\
\hline Creatininase inhibitor & 0.805 & - & 0.667 & - & 0.736 & - & - \\
\hline Cyanoalanine nitrilase inhibitor & - & - & 0.613 & - & - & - & 0.526 \\
\hline Cysteamine dioxygenase inhibitor & - & - & - & 0.557 & - & 0.524 & 0.533 \\
\hline $\begin{array}{c}\text { Dehydro- } \\
\text { L-gulonate decarboxylase } \\
\text { inhibitor }\end{array}$ & 0.82 & 0.764 & 0.74 & 0.655 & 0.791 & 0.607 & 0.655 \\
\hline $\begin{array}{l}\text { 2,4-Dichlor- } \\
\text { ophenol 6-monooxygenase } \\
\text { inhibitor }\end{array}$ & - & - & - & 0.57 & - & 0.589 & 0.598 \\
\hline
\end{tabular}


Continuation of Table 2

\begin{tabular}{|c|c|c|c|c|c|c|c|}
\hline 1 & 2 & 3 & 4 & 5 & 6 & 7 & 8 \\
\hline $\begin{array}{c}\text { Electron-transferring- } \\
\text { flavoprotein dehydrogenase } \\
\text { inhibitor }\end{array}$ & - & - & 0.555 & 0.717 & - & 0.69 & - \\
\hline Endopeptidase So inhibitor & 0.774 & 0.76 & 0.699 & 0.776 & 0.742 & 0.792 & 0.682 \\
\hline $\begin{array}{c}\text { Ferredoxin hydrogenase } \\
\text { inhibitor }\end{array}$ & - & - & 0.548 & - & - & - & - \\
\hline $\begin{array}{l}\text { Ferredoxin-NAD+ } \\
\text { reductase inhibitor }\end{array}$ & 0.756 & - & 0.653 & - & 0.716 & - & 0.553 \\
\hline Fibrolase inhibitor & - & - & 0.547 & - & - & - & 0.58 \\
\hline $\begin{array}{c}\text { Formaldehyde } \\
\text { dehydrogenase inhibitor }\end{array}$ & - & - & - & - & - & 0.511 & - \\
\hline Fragilysin inhibitor & 0.788 & 0.826 & 0.673 & 0.779 & 0.747 & 0.745 & 0.848 \\
\hline $\begin{array}{c}\text { Fructose 5-dehydrogenase } \\
\text { inhibitor }\end{array}$ & - & - & 0.547 & - & 0.785 & - & - \\
\hline $\begin{array}{c}\text { Gamma- } \\
\text { guanidinobutyraldehyde } \\
\text { dehydrogenase inhibitor }\end{array}$ & 0.817 & 0.752 & 0.72 & 0.622 & - & 0.572 & 0.622 \\
\hline $\begin{array}{l}\text { Gluconate 2-dehydrogenase } \\
\text { (acceptor) inhibitor }\end{array}$ & - & - & 0.644 & - & - & - & - \\
\hline $\begin{array}{c}\text { Glutathione thiolesterase } \\
\text { inhibitor } \\
\end{array}$ & 0.786 & 0.716 & 0.689 & 0.588 & 0.749 & - & 0.588 \\
\hline $\begin{array}{l}\text { Glycosylphosphatidylinositol } \\
\text { phospholipase D inhibitor }\end{array}$ & 0.914 & 0.843 & 0.876 & 0.821 & 0.861 & 0.798 & 0.777 \\
\hline $\begin{array}{c}\text { Glyceryl-ether } \\
\text { monooxygenase inhibitor }\end{array}$ & - & - & 0.561 & 0.642 & - & 0.663 & 0.581 \\
\hline $\begin{array}{c}\text { Gly-X carboxypeptidase } \\
\text { inhibitor } \\
\end{array}$ & - & - & 0.596 & 0.552 & - & 0.508 & 0.552 \\
\hline Guanidinoacetase inhibitor & - & - & 0.541 & 0.587 & - & 0.628 & - \\
\hline $\begin{array}{c}\text { Histidinol-phosphatase } \\
\text { inhibitor } \\
\end{array}$ & - & - & 0.542 & - & - & - & - \\
\hline Horrilysin inhibitor & - & - & 0.558 & - & - & - & 0.499 \\
\hline $\begin{array}{l}\text { Hydroxylamine oxidase } \\
\text { inhibitor } \\
\end{array}$ & 0.71 & - & 0.617 & 0.647 & - & 0.67 & 0.536 \\
\hline $\begin{array}{c}\text { IgA-specific } \\
\text { metalloendopeptidase } \\
\text { inhibitor } \\
\end{array}$ & 0.869 & 0.849 & 0.786 & 0.861 & 0.832 & 0.877 & 0.755 \\
\hline $\begin{array}{c}\text { 3-Isopropyl- } \\
\text { malate dehydratase inhibitor }\end{array}$ & - & - & - & - & - & - & 0.53 \\
\hline $\begin{array}{l}\text { Linoleate diol synthase } \\
\text { inhibitor } \\
\end{array}$ & - & - & - & - & - & - & 0.56 \\
\hline $\begin{array}{l}\text { Linoleoyl-CoA desaturase } \\
\text { inhibitor }\end{array}$ & - & - & - & - & - & - & 0.554 \\
\hline Leucolysin inhibitor & 0.732 & 0.752 & 0.601 & 0.63 & 0.727 & 0.577 & 0.63 \\
\hline Lysostaphin inhibitor & 0.763 & - & 0.657 & - & - & - & 0.554 \\
\hline $\begin{array}{l}\text { Manganese peroxidase } \\
\text { inhibitor }\end{array}$ & - & - & 0.529 & - & - & - & - \\
\hline Meprin B inhibitor & - & - & 0.502 & - & - & - & - \\
\hline $\begin{array}{c}\text { Methanol dehydrogenase } \\
\text { inhibitor }\end{array}$ & - & - & 0.562 & - & - & - & - \\
\hline $\begin{array}{c}\text { 4-Metho- } \\
\text { xybenzoate monooxygenase } \\
\text { (O-demethylating) inhibitor }\end{array}$ & - & - & - & - & - & - & 0.521 \\
\hline $\begin{array}{l}\text { Monodehydroascorbate } \\
\text { reductase (NADH) inhibitor }\end{array}$ & - & - & 0.561 & 0.585 & - & - & - \\
\hline
\end{tabular}


Continuation of Table 2

\begin{tabular}{|c|c|c|c|c|c|c|c|}
\hline 1 & 2 & 3 & 4 & 5 & 6 & 7 & 8 \\
\hline Mucomembranous protector & - & - & 0.64 & - & - & - & 0.598 \\
\hline $\begin{array}{c}\text { Naphthalene } \\
\text { 1,2-dioxygenase inhibitor }\end{array}$ & 0.756 & - & 0.653 & - & 0.716 & 0.606 & 0.553 \\
\hline $\begin{array}{c}\text { N-benzyloxycarbonylglycine } \\
\text { hydrolase inhibitor }\end{array}$ & 0.83 & 0.81 & 0.725 & 0.747 & - & 0.697 & 0.683 \\
\hline $\begin{array}{c}\text { N-carbamoyl-L-amino-acid } \\
\text { hydrolase inhibitor }\end{array}$ & 0.78 & 0.746 & 0.679 & 0.636 & 0.724 & 0.591 & 0.636 \\
\hline $\begin{array}{c}\text { Nicotine dehydrogenase } \\
\text { inhibitor }\end{array}$ & 0.729 & - & 0.654 & 0.586 & - & 0.559 & 0.551 \\
\hline $\begin{array}{l}\text { Nicotinic alpha-6beta-3beta- } \\
\text { 4-alpha-5- receptor antagonist }\end{array}$ & - & - & 0.581 & - & - & - & - \\
\hline $\begin{array}{c}\text { Nicotinic alpha4beta4 receptor } \\
\text { agonist }\end{array}$ & - & - & - & - & - & - & 0.558 \\
\hline $\begin{array}{c}\text { Nitrate reductase } \\
\text { (cytochrome) inhibitor }\end{array}$ & 0.781 & 0.804 & 0.663 & 0.797 & 0.72 & 0.809 & 0.696 \\
\hline $\begin{array}{l}\text { P-benzoquinone reductase } \\
\text { (NADPH) inhibitor }\end{array}$ & - & - & 0.534 & - & - & - & - \\
\hline $\begin{array}{c}\text { Peptidyl-dipeptidase } \\
\text { Dcp inhibitor }\end{array}$ & - & - & - & - & - & - & 0.6 \\
\hline $\begin{array}{c}\text { Phthalate 4,5-dioxygenase } \\
\text { inhibitor }\end{array}$ & 0.857 & 0.753 & 0.8 & 0.671 & 0.778 & 0.64 & 0.671 \\
\hline Peroxidase inhibitor & - & - & - & - & - & - & 0.584 \\
\hline $\begin{array}{c}\text { Polyneuridine-aldehyde } \\
\text { esterase inhibitor }\end{array}$ & 0.71 & - & 0.575 & 0.559 & - & - & 0.559 \\
\hline $\begin{array}{c}\text { Procollagen N-endopeptidase } \\
\text { inhibitor }\end{array}$ & - & - & - & - & - & 0.52 & - \\
\hline Pseudolysin inhibitor & 0.725 & - & 0.637 & 0.604 & - & 0.573 & 0.689 \\
\hline Pullulanase inhibitor & 0.797 & 0.722 & 0.626 & 0.756 & - & 0.786 & - \\
\hline $\begin{array}{c}\text { Rhamnulose-1-phosphate } \\
\text { aldolase inhibitor }\end{array}$ & 0.79 & - & 0.647 & 0.671 & 0.716 & 0.709 & - \\
\hline $\begin{array}{c}\text { Salicylate 1-monooxygenase } \\
\text { inhibitor }\end{array}$ & - & - & 0.546 & - & - & - & - \\
\hline Snapalysin inhibitor & - & - & - & - & - & - & 0.532 \\
\hline Sulfur reductase inhibitor & - & 0.711 & 0.6 & 0.72 & - & 0.733 & 0.632 \\
\hline $\begin{array}{c}\text { Superoxide dismutase } \\
\text { inhibitor }\end{array}$ & 0.753 & 0.754 & 0.655 & 0.738 & 0.76 & 0.762 & 0.579 \\
\hline $\begin{array}{c}\text { Quercetin 2,3-dioxygenase } \\
\text { inhibitor }\end{array}$ & - & - & - & - & - & - & 0.494 \\
\hline Thioredoxin inhibitor & 0.778 & 0.753 & 0.695 & 0.786 & 0.862 & 0.761 & 0.664 \\
\hline $\begin{array}{l}\text { tRNA-pseudouridine synthase } \\
\text { I inhibitor }\end{array}$ & 0.759 & - & 0.654 & 0.558 & 0.722 & - & 0.558 \\
\hline Tryptophanamidase inhibitor & 0.763 & 0.728 & 0.621 & - & - & & 0.549 \\
\hline Urethanase inhibitor & - & - & 0.522 & 0.607 & - & 0.64 & 0.586 \\
\hline Venom exonuclease inhibitor & - & - & 0.515 & - & - & - & 0.492 \\
\hline $\begin{array}{l}\mathrm{X} \text {-methyl-His dipeptidase } \\
\text { inhibitor }\end{array}$ & - & - & - & - & - & - & 0.574 \\
\hline
\end{tabular}


For a number of S-alkyl esters of 8-quinoline thiosulfonic acid there is a general pattern of decreasing activity with increasing length of the alkyl chain. Accordingly, the leader among them is the S-methyl ester of 8-quinolinethiosulfonic acids. For all esters inhibitory activity against Thioredoxin, Superoxide dismutase, Phthalate 4,5-dioxygenase, Nitrate reductase (cytochrome), N-carbamoyl-L-amino-acid hydrolase, Leucolysin, IgA-specific metalloendopeptidase, Glycosylphosphatipidipididinase Fragilysin, Carboxypeptidase Taq, Dehydro-L-gulonate decarboxylase, Arylacetonitrilase, Arylalkyl acylamidase, (R) -6-hydroxynicotine oxidase, (S) -6-hydroxynicotine oxidase.

Table 3

The predicted effect of the biological action of S-alkyl esters of 8-hydroxyquinoline thiosulfonic acid $25 a-c$ according to PASS program

\begin{tabular}{|c|c|c|c|}
\hline \multirow{2}{*}{ Activity } & \multicolumn{3}{|c|}{ Number of the compound } \\
\hline & $-\mathrm{CH}_{3}$ & $-\mathrm{C}_{2} \mathrm{H}_{5}$ & $-\mathrm{C}_{3} \mathrm{H}_{5}$ \\
\hline (R)-6-hydroxynicotine oxidase inhibitor & 0.742 & - & 0.637 \\
\hline (S)-3-hydroxyacid ester dehydrogenase inhibitor & 0.817 & 0.754 & 0.729 \\
\hline (S)-6-hydroxynicotine oxidase inhibitor & 0.746 & - & 0.622 \\
\hline 2-Hydroxyquinoline 8-monooxygenase inhibitor & 0.722 & - & 0.655 \\
\hline 2,4-Dichlorophenol 6-monooxygenase inhibitor & - & - & 0.513 \\
\hline Alkane 1-monooxygenase inhibitor & 0.817 & 0.811 & 0.787 \\
\hline Antiseborrheic & 0.765 & 0.851 & 0.704 \\
\hline Antifungal & - & - & 0.529 \\
\hline Apoptosis agonist & - & - & 0.595 \\
\hline Arylacetonitrilase inhibitor & 0.883 & 0.916 & 0.839 \\
\hline Aspulvinone dimethylallyltransferase inhibitor & 0.712 & - & 0.644 \\
\hline Carboxypeptidase Taq inhibitor & - & - & 0.632 \\
\hline $\begin{array}{l}\text { Cis-1,2-dihydro-1,2-dihydroxynaphthalene } \\
\text { dehydrogenase inhibitor }\end{array}$ & 0.765 & - & 0.633 \\
\hline Corticosteroid side-chain-isomerase inhibitor & 0.792 & 0.72 & 0.675 \\
\hline Cysteamine dioxygenase inhibitor & 0.751 & 0.791 & 0.688 \\
\hline Dehydro-L-gulonate decarboxylase inhibitor & 0.879 & 0.875 & 0.859 \\
\hline $\begin{array}{l}\text { Gamma-guanidinobutyraldehyde dehydrogenase } \\
\text { inhibitor }\end{array}$ & 0.72 & 0.714 & 0.67 \\
\hline Glucose oxidase inhibitor & 0.731 & - & - \\
\hline Glutathione thiolesterase inhibitor & 0.856 & 0.85 & 0.831 \\
\hline Glyceryl-ether monooxygenase inhibitor & 0.887 & 0.884 & 0.865 \\
\hline $\begin{array}{c}\text { Glycosylphosphatidylinositol phospholipase } \\
\text { D inhibitor }\end{array}$ & 0.804 & 0.721 & 0.687 \\
\hline Guanidinoacetase inhibitor & 0.775 & 0.745 & 0.708 \\
\hline Histidinol-phosphatase inhibitor & 0.776 & 0.746 & 0.709 \\
\hline Hydroxylamine oxidase inhibitor & 0.767 & 0.755 & 0.729 \\
\hline IgA-specific metalloendopeptidase inhibitor & - & - & 0.565 \\
\hline Indanol dehydrogenase inhibitor & - & - & 0.605 \\
\hline Methylaspartate ammonia-lyase inhibitor & - & - & 0.553 \\
\hline $\begin{array}{l}\text { 4-Methoxybenzoate monooxygenase } \\
\text { (O-demethylating) inhibitor }\end{array}$ & - & - & 0.67 \\
\hline
\end{tabular}


Continuation of Table 3

\begin{tabular}{|c|c|c|c|}
\hline \multirow{2}{*}{ Activity } & \multicolumn{3}{|c|}{ Number of the compound } \\
\hline & $-\mathrm{CH}_{3}$ & $-\mathrm{C}_{2} \mathrm{H}_{5}$ & $-\mathrm{C}_{3} \mathrm{H}_{5}$ \\
\hline $\begin{array}{c}\text { Monodehydroascorbate reductase (NADH) } \\
\text { inhibitor }\end{array}$ & 0.825 & 0.892 & 0.822 \\
\hline Mucomembranous protector & - & - & - \\
\hline N-carbamoyl-L-amino-acid hydrolase inhibitor & 0.796 & 0.821 & 0.743 \\
\hline Nicotinic alpha4beta4 receptor agonist & - & - & - \\
\hline Nicotine dehydrogenase inhibitor & 0.79 & 0.75 & 0.726 \\
\hline Nitrate reductase (cytochrome) inhibitor & - & - & - \\
\hline Nitrilase inhibitor & - & 0.745 & - \\
\hline Nucleoside oxidase $\left(\mathrm{H}_{2} \mathrm{O}_{2}\right.$-forming) inhibitor & - & - & 0.533 \\
\hline Quercetin 2,3-dioxygenase inhibitor & - & 0.774 & - \\
\hline P-benzoquinone reductase (NADPH) inhibitor & 0.764 & - & 0.652 \\
\hline Phosphoglycerate mutase inhibitor & - & & 0.587 \\
\hline Phthalate 4,5-dioxygenase inhibitor & 0.729 & - & 0.611 \\
\hline Rhamnulose-1-phosphate aldolase inhibitor & 0.89 & 0.878 & - \\
\hline Platelet activating factor antagonist & - & - & 0.511 \\
\hline Platelet aggregation inhibitor & - & - & 0.682 \\
\hline Porphobilinogen synthase inhibitor & - & - & 0.587 \\
\hline Quercetin 2,3-dioxygenase inhibitor & - & - & 0.6 \\
\hline Rhamnulose-1-phosphate aldolase inhibitor & - & - & 0.859 \\
\hline Steroid 9alpha-monooxygenase inhibitor & - & - & 0.603 \\
\hline Sulfite reductase inhibitor & - & - & 0.589 \\
\hline Sulfur reductase inhibitor & - & - & 0.559 \\
\hline Thiol oxidase inhibitor & - & 0.711 & 0.525 \\
\hline Thioredoxin inhibitor & - & 0.729 & 0.643 \\
\hline TRPA1 agonist & - & - & - \\
\hline UGT2B12 substrate & 0.817 & 0.791 & 0.779 \\
\hline Venom exonuclease inhibitor & 0.734 & 0.771 & 0.629 \\
\hline
\end{tabular}

The leader among the S-alkyl esters of 8-hydroxyquinoline thiosulfonic acids is also the S-methyl ester of 8-hydroxyquinoline thiosulfonic acids. For all esters inhibitory activity against Venom exonuclease, N-carbamoyl-L-amino-acid hydrolase, Nicotine dehydrogenase, Monodehydroascorbate reductase (NADH), Glycosylphosphatidylinositol phospholipase D, Guanidinoacetase, Histidinolphosphatase, Hydroxylamine oxidase, Glutathione thiolesterase, Glyceryl-ether monooxygenase, Gamma-guanidinobutyraldehyde dehydrogenase, Corticosteroid side-chain-isomerase, Cysteamine dioxygenase, DehydroL-gulonate decarboxylase, Arylacetonitrilase, (S)-3-hydroxyacid ester dehydrogenase, Alkane 1-monooxygenase, and UGT2B12 substrate, Antiseborrheic activities are also predicted. 
For the methyl, ethyl and allyl esters of 8-quinoline thiosulfonic acids, experimental studies were conducted on their antibacterial and fungicidal activities on E. coli C-600, Candida albicans test cultures table 3.

Table 4

Sensitivity of test cultures to synthesized thiosulfonates $18 \mathrm{a}-\mathrm{g}$

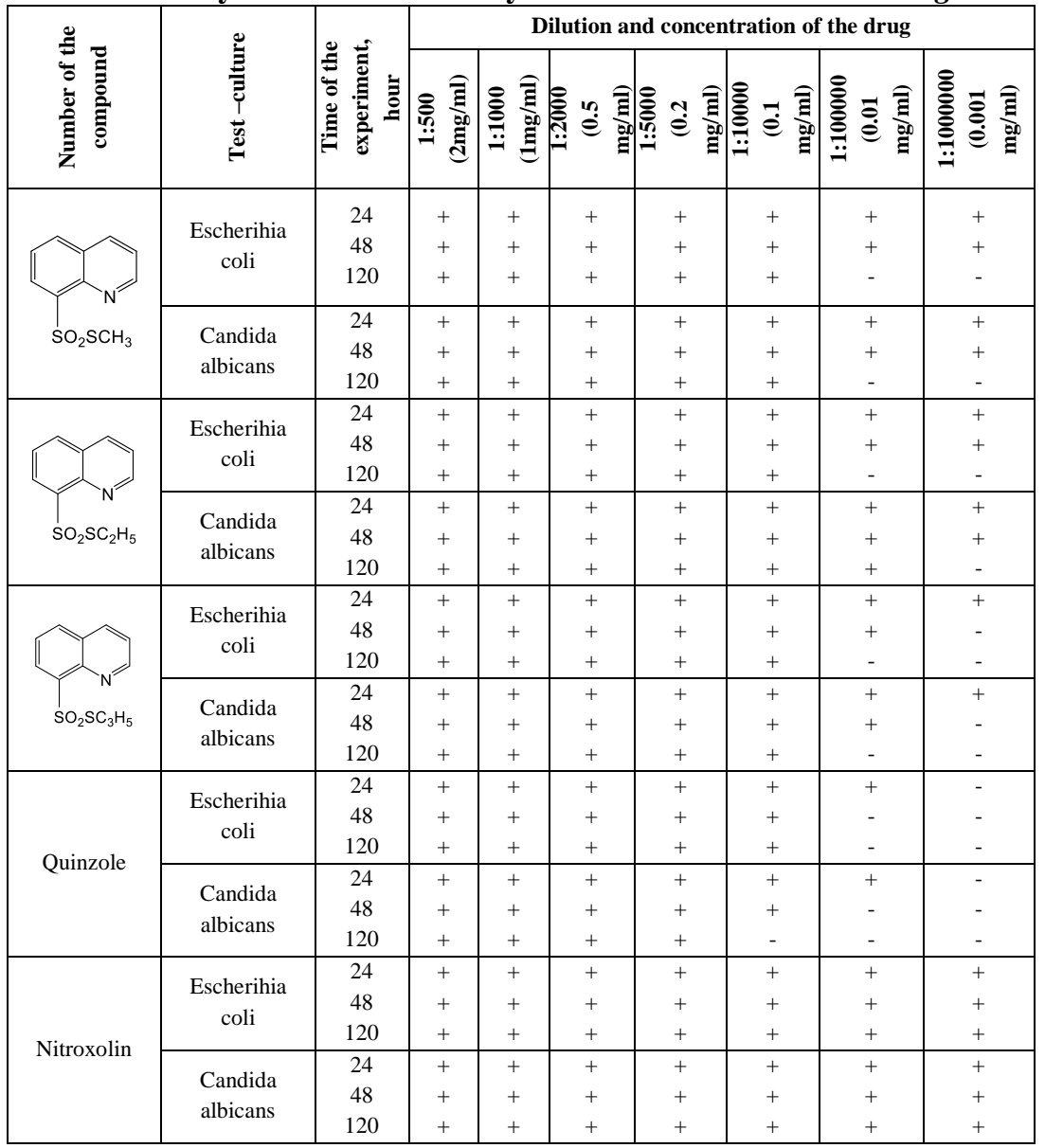

Note: + complete delay in the development of test cultures (fungicide); + partial delay in the development of test cultures (fungibacteristic; - no influence of the drug, active growth of test culture 


\section{Cytotoxicity}

CLC-Pred (Cell Line Cytotoxicity Predictor) is a web-service for in silico prediction of cytotoxic effect of chemical compounds in nontransformed and cancer cell lines based on structural formula. CLC-Pred provides a prediction of the cytotoxicity of a chemical compound to assess the relevance of the substance's inclusion in experimental screening.

The cytotoxicity of the test compounds was tested for lung cancer, breast, skin, and blood cell lines.

Table 5

\section{Predicted cytotoxicity of 4-amino-2-methylpyrimidin-5-yl-methyl esters} of thiosulfonic acids $12 a-d$

\begin{tabular}{|c|c|c|c|c|c|}
\hline Cell line & $\begin{array}{c}\text { Full name of the } \\
\text { cell line }\end{array}$ & \multicolumn{4}{|c|}{ The value of $\mathrm{Pa}$ for the corresponding compound } \\
\hline & & $\Pi-\mathrm{C}_{6} \mathrm{H}_{5}$ & $\Pi-\mathrm{ClC}_{6} \mathrm{H}_{4}$ & $\Pi-\mathrm{NH}_{2} \mathrm{C}_{6} \mathrm{H}_{4}$ & $\Pi-\mathrm{CH}_{3} \mathrm{COONHC}_{6} \mathrm{H}_{4}$ \\
\hline SR & $\begin{array}{c}\text { Adult } \\
\text { immunoblastic } \\
\text { lymphoma }\end{array}$ & 0.806 & 0.791 & 0.792 & 0.621 \\
\hline HOP-92 & $\begin{array}{c}\text { Non-small cell } \\
\text { lung carcinoma }\end{array}$ & 0.687 & 0.702 & 0.656 & - \\
\hline NCI- \\
H522 & $\begin{array}{c}\text { Non-small cell } \\
\text { lung carcinoma }\end{array}$ & 0.650 & 0.642 & 0.630 & 0.567 \\
\hline MOLT-4 & $\begin{array}{c}\text { Acute } \\
\text { T-lymphoblastic } \\
\text { leukemia }\end{array}$ & 0.632 & 0.612 & 0.668 & - \\
\hline IGROV-1 & $\begin{array}{c}\text { Ovarian } \\
\text { adenocarcinoma }\end{array}$ & 0.565 & 0.530 & 0.533 & - \\
\hline T47D & $\begin{array}{c}\text { Breast } \\
\text { carcinoma }\end{array}$ & - & 0.505 & - & - \\
\hline
\end{tabular}

As a result of the analysis, the cytotoxicity of 4-amino-2methylpyrimidin-5-yl-methyl thiosulfonic acid esters revealed that 4-amino2-methyl-pyrimidin-5-yl-methyl ester of 4-chlorobenzenethiosulfonic acid exhibited the broadest protein activity. However, the highest values of activity indicators are 4-amino-2-methylpyrimidin-5-yl-methyl ester of 4-benzenethiosulfonic acid. 
Table 6

The predicted cytotoxicity of S-alkyl esters of 8-quinoline

thiosulfonic acid $18 \mathrm{a}-\mathrm{g}$

\begin{tabular}{|c|c|c|c|c|c|c|c|c|}
\hline \multirow[b]{2}{*}{ Cell line } & \multirow[b]{2}{*}{$\begin{array}{l}\text { Full name of } \\
\text { the cell line }\end{array}$} & \multicolumn{7}{|c|}{ The value of the Pa for the corresponding compound } \\
\hline & & $-\mathrm{CH}_{3}$ & $-\mathrm{C}_{2} \mathrm{H}_{5}$ & $-\mathrm{C}_{3} \mathrm{H}_{5}$ & $-\mathrm{C}_{3} \mathrm{H}_{7}$ & $\begin{array}{c}-\mathrm{C}_{3} \mathrm{H}_{7} \\
\text { iso }\end{array}$ & $-\mathrm{C}_{4} \mathrm{H}_{9}$ & $\begin{array}{c}-\mathrm{C}_{4} \mathrm{H}_{9} \\
\text { iso }\end{array}$ \\
\hline 1 & 2 & 3 & 4 & 5 & 6 & 7 & 8 & 9 \\
\hline SR & $\begin{array}{c}\text { Adult } \\
\text { immunoblastic } \\
\text { lymphoma }\end{array}$ & 0.988 & 0.987 & 0.985 & 0.980 & 0.984 & 0.974 & 0.977 \\
\hline A549 & Lung carcinoma & 0.990 & 0.966 & 0.969 & 0.942 & 0.903 & 0.938 & 0.955 \\
\hline NCI-H522 & $\begin{array}{l}\text { Non-small cell } \\
\text { lung carcinoma }\end{array}$ & 0.954 & 0.951 & 0.943 & 0.909 & 0.918 & 0.901 & 0.912 \\
\hline HOP-92 & $\begin{array}{l}\text { Non-small cell } \\
\text { lung carcinoma }\end{array}$ & 0.937 & 0.936 & 0.925 & 0.892 & 0.896 & 0.886 & 0.932 \\
\hline SK-MEL-5 & Melanoma & 0.935 & 0.931 & 0.919 & 0.889 & 0.895 & 0.883 & 0.891 \\
\hline IGROV-1 & $\begin{array}{c}\text { Ovarian } \\
\text { adenocarcinoma }\end{array}$ & 0.868 & 0.869 & 0.839 & 0.817 & 0.741 & 0.830 & 0.859 \\
\hline MOLT-4 & $\begin{array}{c}\text { Acute } \\
\text { T-lymphoblastic } \\
\text { leukemia }\end{array}$ & 0.836 & 0.847 & 0.850 & 0.730 & 0.800 & 0.713 & 0.830 \\
\hline UACC-257 & Melanoma & 0.809 & 0.828 & 0.803 & 0.709 & 0.693 & 0.701 & 0.705 \\
\hline HCC 2998 & $\begin{array}{c}\text { Colon } \\
\text { adenocarcinoma }\end{array}$ & 0.795 & 0.831 & 0.728 & 0.687 & 0.637 & 0.674 & 0.696 \\
\hline MCF7 & $\begin{array}{c}\text { Breast } \\
\text { carcinoma }\end{array}$ & 0.755 & 0.694 & 0.692 & 0.684 & 0.886 & 0.748 & 0.669 \\
\hline Malme-3M & Melanoma & 0.737 & 0.766 & 0.738 & 0.731 & 0.668 & 0.687 & 0.690 \\
\hline $786-0$ & $\begin{array}{c}\text { Renal } \\
\text { carcinoma }\end{array}$ & 0.735 & 0.764 & 0.721 & 0.719 & 0.626 & 0.651 & 0.672 \\
\hline HL-60 & $\begin{array}{c}\text { Promyeloblast } \\
\text { leukemia }\end{array}$ & 0.512 & - & - & - & - & - & - \\
\hline T47D & $\begin{array}{c}\text { Breast } \\
\text { carcinoma }\end{array}$ & - & - & - & - & 0.785 & - & - \\
\hline $\begin{array}{l}\text { MDA-MB- } \\
231\end{array}$ & $\begin{array}{c}\text { Breast } \\
\text { adenocarcinoma }\end{array}$ & - & - & - & - & 0.604 & - & - \\
\hline
\end{tabular}

When analyzing the results of the predicted cytotoxicity of S-alkyl esters of 8-quinoline thiosulphonic acid, it was found that only S-isopropyl ester of 8quinoline thiosulphonic acids showed activity against the lines Breast carcinoma (T47D) and Breast adenocarcinoma 23 (MDA). However, the width of the spectrum of cytotoxic action and the value of predicted activity $(\mathrm{Pa})$ is the leader of S-methyl ester of 8-quinoline thiosulfonic acids. In general, there is a decrease in $\mathrm{Ra}$ indices with increasing length of the hydrocarbon radical. 
The predicted cytotoxicity of S-alkyl esters of 8-hydroxyquinoline thiosulfonic acids 25 a-c

\begin{tabular}{|c|c|c|c|c|}
\hline \multirow{2}{*}{ Cell line } & \multirow{2}{*}{ Full name of the cell line } & \multicolumn{3}{|c|}{$\begin{array}{c}\text { The value of the Pa for the } \\
\text { corresponding compound }\end{array}$} \\
\cline { 3 - 5 } & & $-\mathbf{C H}_{\mathbf{3}}$ & $-\mathbf{C}_{\mathbf{2}} \mathbf{H}_{\mathbf{5}}$ & $\mathbf{- C}_{\mathbf{3}} \mathbf{H}_{\mathbf{5}}$ \\
\hline SR & Adult immunoblastic lymphoma & 0.978 & 0.976 & 0.971 \\
\hline A549 & Lung carcinoma & 0.978 & 0.937 & 0.945 \\
\hline NCI-H522 & Non-small cell lung carcinoma & 0.902 & 0.899 & 0.885 \\
\hline SK-MEL-5 & Melanoma & 0.886 & 0.885 & 0.874 \\
\hline HOP-92 & Non-small cell lung carcinoma & 0.880 & 0.883 & 0.867 \\
\hline MCF7 & Breast carcinoma & 0.823 & 0.780 & 0.776 \\
\hline MOLT-4 & Acute T-lymphoblastic leukemia & 0.787 & 0.810 & 0.815 \\
\hline IGROV-1 & Ovarian adenocarcinoma & 0.773 & 0.780 & 0.753 \\
\hline Malme-3M & Melanoma & 0.680 & 0.706 & 0.685 \\
\hline UACC-257 & Melanoma & 0.665 & 0.699 & 0.669 \\
\hline 786-0 & Renal carcinoma & 0.634 & 0.680 & 0.628 \\
\hline HCC 2998 & Colon adenocarcinoma & 0.627 & 0.687 & 0.589 \\
\hline HL-60 & Promyeloblast leukemia & 0.502 & - & - \\
\hline
\end{tabular}

The spectrum of cytotoxic action and the predicted activity ( $\mathrm{Ra}$ ) of the leader is S-methyl ester of 8-hydroxyquinoline thiosulfonic acid, however, for some lines of colon cancer cells, kidneys, melanoma, ovaries, blood, lungs, S-ethylthioxy ester is more active than S-ethyloxy ester.

\section{Acute rat toxicity prediction}

GUSAR software was developed to create QSAR/QSPR models on the basis of the appropriate training sets represented as SDfile contained data about chemical structures and endpoint in quantitative terms.

QSAR was used to model acute toxicity of rats based on a combination of QNA descriptors (Quantitative Neighborhood Atoms). This method allows the prediction of $L D_{50}$ values for compounds by four types of administration (oral, intravenous, intraperitoneal, subcutaneous).

It is common practice to devide chemicals by toxicity into the following classes: extremely toxic, highly toxic, highly toxic, moderately toxic, low toxic, non-toxic. 
Table 8

Predicted acute toxicity for rats relative to the type of administration and toxicity class of test esters 12 a-d, 18 a-g, $25 a-c$

\begin{tabular}{|c|c|c|c|c|c|}
\hline \multicolumn{2}{|c|}{ Compound } & $\begin{array}{c}\text { Rat IP } \\
\text { LD }_{50}\end{array}$ & $\begin{array}{c}\text { Rat IV } \\
\text { LD }_{50} \log 10\end{array}$ & $\begin{array}{c}\text { Rat Oral } \\
\text { LD }_{50} \log 10\end{array}$ & $\begin{array}{c}\text { Rat SC } \\
\text { LD }_{50} \log 10\end{array}$ \\
\hline \multicolumn{2}{|l|}{1} & 2 & 3 & 4 & 5 \\
\hline \multirow[b]{3}{*}{$\mathrm{SO}_{2} \mathrm{SHCH}_{3}$} & $\mathrm{mmol} / \mathrm{kg}$ & -0.051 & 0.164 & 0.268 & -0.027 \\
\hline & $\mathrm{mg} / \mathrm{kg}$ & 212.800 & 348.800 & 443.700 & 224.900 \\
\hline & Class & 4 & 5 & 4 & 4 \\
\hline \multirow[b]{3}{*}{$\mathrm{SO}_{2} \mathrm{SHC}_{2} \mathrm{H}_{5}$} & $\mathrm{mmol} / \mathrm{kg}$ & 0.199 & 0.150 & 0.310 & 0.246 \\
\hline & $\mathrm{mg} / \mathrm{kg}$ & 400.300 & 357.900 & 517.200 & 445.900 \\
\hline & Class & 4 & 5 & 4 & 4 \\
\hline \multirow[b]{3}{*}{$\mathrm{SO}_{2} \mathrm{SHC}_{3} \mathrm{H}_{5}$} & $\mathrm{mmol} / \mathrm{kg}$ & 0.261 & 0.174 & 0.319 & 0.198 \\
\hline & $\mathrm{mg} / \mathrm{kg}$ & 483.500 & 396.000 & 553.400 & 418.800 \\
\hline & Class & 4 & 5 & 4 & 4 \\
\hline \multirow[b]{3}{*}{$\mathrm{SO}_{2} \mathrm{SHC}_{3} \mathrm{H}_{7}$} & $\mathrm{mmol} / \mathrm{kg}$ & 0.265 & 0.172 & 0.427 & 0.217 \\
\hline & $\mathrm{mg} / \mathrm{kg}$ & 492.400 & 397.200 & 713.900 & 440.800 \\
\hline & Class & 4 & 5 & 4 & 4 \\
\hline \multirow{3}{*}{$\prod_{\mathrm{CH}_{3}}^{\mathrm{SO}_{2} \mathrm{SHCH}-\mathrm{CH}_{3}}$} & $\mathrm{mmol} / \mathrm{kg}$ & 0.302 & 0.189 & 0.399 & 0.143 \\
\hline & $\mathrm{mg} / \mathrm{kg}$ & 536.500 & 412.900 & 670.800 & 371.900 \\
\hline & Class & 5 & 5 & 4 & 4 \\
\hline \multirow[b]{3}{*}{$\mathrm{SO}_{2} \mathrm{SHC}_{4} \mathrm{H}_{9}$} & $\mathrm{mmol} / \mathrm{kg}$ & 0.234 & 0.004 & 0.499 & 0.323 \\
\hline & $\mathrm{mg} / \mathrm{kg}$ & 482.500 & 284.300 & 887.400 & 591.700 \\
\hline & Class & 4 & 4 & 4 & 4 \\
\hline \multirow[b]{3}{*}{$\begin{array}{c}\mathrm{SO}_{2} \mathrm{SH}-\mathrm{CH}_{2}-\mathrm{CH}-\mathrm{CH}_{3} \\
\mathrm{CH}_{3}\end{array}$} & $\mathrm{mmol} / \mathrm{kg}$ & 0.278 & 0.044 & 0.253 & 0.197 \\
\hline & $\mathrm{mg} / \mathrm{kg}$ & 533.600 & 311.700 & 503.900 & 442.500 \\
\hline & Class & 5 & 5 & 4 & 4 \\
\hline
\end{tabular}


Continuation of Table 8

\begin{tabular}{|c|c|c|c|c|c|}
\hline \multicolumn{2}{|l|}{1} & 2 & 3 & 4 & 5 \\
\hline & $\mathrm{mmol} / \mathrm{kg}$ & 0.045 & -0.087 & 0.180 & 0.505 \\
\hline & $\mathrm{mg} / \mathrm{kg}$ & 314.300 & 232.000 & 429.300 & 907.400 \\
\hline & Class & 4 & 4 & 4 & 4 \\
\hline $\mathrm{C}_{4} \mathrm{H}_{9}$ & $\mathrm{mmol} / \mathrm{kg}$ & 0.038 & -0.198 & 0.405 & 0.488 \\
\hline & $\mathrm{mg} / \mathrm{kg}$ & 324.300 & 188.700 & 756.500 & 915.400 \\
\hline & Class & 4 & 4 & 4 & 4 \\
\hline & $\mathrm{mmol} / \mathrm{kg}$ & 0.100 & 0.215 & 0.196 & 0.745 \\
\hline & $\mathrm{mg} / \mathrm{kg}$ & 372.000 & 485.100 & 463.600 & 1641.000 \\
\hline & Class & 4 & 5 & 4 & 5 \\
\hline & $\mathrm{mmol} / \mathrm{kg}$ & 0.070 & 0.269 & 0.483 & 0.906 \\
\hline & $\mathrm{mg} / \mathrm{kg}$ & 387.600 & 613.200 & 1004.000 & 2659.000 \\
\hline & Class & 4 & 5 & 4 & Non Toxic \\
\hline & $\mathrm{mmol} / \mathrm{kg}$ & 0.031 & 0.431 & 0.449 & 0.803 \\
\hline & $\mathrm{mg} / \mathrm{kg}$ & 333.400 & 837.300 & 873.400 & 1970.000 \\
\hline & Class & 4 & Non Toxic & 4 & 5 \\
\hline & $\mathrm{mmol} / \mathrm{kg}$ & -0.263 & 0.088 & 0.476 & 0.814 \\
\hline & $\mathrm{mg} / \mathrm{kg}$ & 201.100 & 451.600 & 1102.000 & 2399.000 \\
\hline & Class & 4 & 5 & 4 & 5 \\
\hline
\end{tabular}

Note: IP - Intraperitoneal route of administration; IV - Intravenous route of administration; Oral-Oral route of administration; SC - Subcutaneous route of administration

The results presented in Table 5 indicate that all tested compounds according to the classification of substances by toxicity, according to SOU 85.2-37-736: 2011, belong to the 4th and 5th toxicity classes, ie moderate and low toxic substances, depending on method of administration.

\section{CONCLUSIONS}

A new approach to the synthesis of promising nitrogen-containing heterocyclic thiosulphoesters is proposed. Methods of synthesis have been investigated and preparatively convenient methods of obtaining new thiosulfonic acid esters - quinoline, 8-hydroxyquinoline and pyrimidine derivatives have been established. This made it possible to purposely 
synthesize thiosulphoesters in which the hetero- or carbocyclic moiety may be located on both thiol and sulfonyl sulfur sides.

The compounds obtained are both valuable reagents in organic synthesis and interesting objects for biological research. The carried out predictive screening of biological activity of the tested compounds accordingg to PASS program indicates the feasibility of conducting experimental studies of antiarrhythmic, antiviral, antiseborrheic, analeptic, anti-inflammatory and antitumor activities, as well as establishing the possibility of their use for the treatment of mucous membrane and inflammation. Given the low toxicity, these substances can be tested on biological sites to further use them as substances for veterinary drugs and medicines.

\section{SUMMARY}

The ways of obtaining pyrimidine thiosulfonic acid esters based on 5-bromomethyl-2-methylpyrimidin-4-amine and 2-amino-6methylpyrimidin-4-ol have been investigated. It has been found that the preparation of thiosulphoesters by chlorosulfonation of basic structures followed by the preparation of the corresponding thiosulphonic acid salts and thiosulphoesters based on them is not suitable for the selected pyrimidines. Thiosulfoesters with a pyrimidine moiety were obtained from the thiol sulfur side by alkylation of 5-bromomethyl-2-methylpyrimidin-4amine thiosulfonic acid salts.

For the synthesis of 8-quinolinesulfonic, 8-hydroxyquinolinesulfonic acid S-esters, quinoline and 8-quinolinesulfonic acid were selected as the starting material, which were converted to 8-quinolinesulfochloride, which was reduced to the sodium or potassium salts of 8-quinolinesulfonic acids. As a result of alkylation of halogen bromides or dialkyl sulfates in acetoneaqueous or alcohol media, the corresponding S-alkyl-8-quinoline thiosulfonates have been synthesized.

Some regularities of structure - activity dependence have been established, which can be used for directed synthesis of biologically active compounds. Among the synthesized thiosulphonates, substances that exhibit antiarrhythmic, antiviral, antiseborrheic, analeptic, anti-inflammatory and antitumor activity were identified using predictive screening, as well as the possibilities of their use for the treatment of mucous membrane, inflammation of the bowel and ankylosing spondylitis. All test substances 
were found to be low toxic according to GUSAR data. The results presented indicate the feasibility of carrying out experimental studies of the biological activity of these substances in order to further use them as substances for veterinary drugs and medicines.

\section{REFERENCES}

1. Shcherbak O.M., Andreieva I.D., Kazmirchuk V.V., Rusak P.S., Menkus O.V. Perspektyvy Zastosuvannia Novykh Pokhidnykh Pirymidynu Pry Nozokomialnykh Infektsiiakh Vyklykanykh Hramnehatyvnymy Mikroorhanizmamy. Ukrainian journal of surgery. 2012. № 3 (18). P. 34-37.

2. Shcherbak O.M. Perspektyvy Vyvchennia Protymikrobnoi Dii Novykh Pokhidnykh 4N-Pirydo4'3'56pirano-23-Dpirymidynu. Aktualni Pytannia Farmatsevtychnoi I Medychnoi Nauky Ta Praktyky. 2011. № 2 (24). P. 116-118.

3. Pietro O.D., Vicente-García E., Taylor M.C., Berenguer D., Viayna E., Lanzoni A., Sola I., Sayago H., Riera C., Fisa R., Clos M.V., Pérez B., Kelly J.M., Lavilla R., Muñoz-Torrero D. Multicomponent reaction-based synthesis and biological evaluation of tricyclic heterofusedquinolines with multi-trypanosomatid activity. European Journal of Medicinal Chemistry. 2015. № 105. P. 120-137. URL: https://doi.org/10.1016/j.ejmech.2015.10.007.

4. Mampuys P., McElroy C.R., Clark J.H., Orru R.V.A., Maes B.U.W. Thiosulfonates as Emerging Reactants: Synthesis and Applications Adv. Synth. Catal. 2020. № 362. P. 3-64. URL: https://doi.org/10.1002/adsc.201901597.

5. Lubenets V., Stadnytska N., Baranovych D., Vasylyuk S., Karpenko O., Havryliak V., Novikov V. Thiosulfonates: The Prospective Substances against Fungal Infections. Fungal Infection / eds. Érico Silva de Loreto and Juliana Simoni Moraes Tondolo. IntechOpen, London, 2019. DOI: 10.5772/intechopen.84436.

6. Pylypets A.Z., Iskra R.Y., Havryliak V.V., Nakonechna A.V., Novikov V.P., Lubenets V.I. Effects of thiosulfonates on the lipid composition of rat tissues. Український біохімічний журнал. 2017. № 89. 6. P. 58-64. doi: https://doi.org/10.15407/ubj89.06.056.

7. Oriabinska L.B., Starovoitova S.O., Vasylyuk S.V., Novikov V.P., Lubenets V.I. Ethylthiosulfanilate effect on Candida tropicalis. Украӥнський 
біохімічний журнал. 2017. Vol. 89. № 5. P. 70-76. doi: https://doi.org/10.15407/ubj89.05.070.

8. Halenova T.I., Nikolaeva I.V., Nakonechna A.V., Bolibrukh K.B., Monka N.Y., Lubenets V.I., Savchuk O.M., Novikov V.P., Ostapchenko L.I. The search of compounds with antiaggregation activity among S-esters of thiosulfonic acids. Ukr. Biochem. J. 2015. № 87. 5. P. 83-92. doi: https://doi.org/10.15407/ubj87.05.083.

9. Lubenets V.I., Stadnitskaya N.Ye., Novikov V.P. Synthesis of thiosulfonates belonging to quinoline derivatives. Russ. J. Org. Chem. 2000. № 36. P. 851-853. DOI: https://doi.org/10.1007/BF02757443.

10. Sato, R., Akutsu, Y., Goto, T., Saito, M. Benzopentathiepin as sulfurization reagent. Novel synthesis of thiosulfonates from sulfinates. Chem. Lett. 1987. № 16. P. 2161-2162.

11. Baranovich D.B., Lubenets V.I., Novikov V.P. Synthesis of thiosulfonates with functional groups in the aliphatic chain. Russ. J. Org. Chem. 2001. № 37. P. 1046-1047.

12. Baranovich D.B., Lubenets V.I., Novikov V.P. Synthesis of S-[2-(4Aminobenzenesulfonyl)ethyl] and S-[2-(3-Amino-4methoxybenzenesulfonyl)ethyl] Thiosulfonates. Russ. J. Gen. Chem. 2001. № 71. P. 1827-1827. DOI: https://doi.org/10.1023/A:1013987618313.

13. Zhao Q., Lu L., Direct Q. Monofluoromethylthiolation with S(Fluoromethyl) Benzenesulfonothioate. Shen, Angew. Chem. 2017. № 129. P. 11733-11736; Angew. Chem. Int. Ed. 2017. № 56. P. 11575-11578. DOI: 10.1002/anie.201705633.

14. Lubenets V.I., Vasylyuk S.V., Novikov V.P. Synthesis of S-(3-chloroquinoxalin-2-yl) esters of aliphatic and aromatic thiosulfonic acids. Chem. Heterocycl. Compd. 2005. № 41. P. 1547-1548. DOI: https://doi.org/10.1007/s10593-006-0039-9.

15. Chura B., Lubenets V.I., Goi O.V., Novikov V.P. The Reaction of Sodium 4-Acetylaminobenzenethiosulfonate with 2,3-Dichloroquinoxaline. Chem. Heterocycl. Compd. 2002. № 38. P. 1432-1433. DOI: 10.1023/A:1022163417299.

16. Lubenets V.I., Vasylyuk S.V., Goi O.V., Novikov V.P. Reaction of 6,7-dichloroquinoline-5,8-quinone with thiosulfonic acid salts. Chem. Heterocycl. Compd. 2006. № 42. P. 961-962. DOI: https://doi.org/10.1007/s10593-006-0189-9 
17. Mashkovskiy M.D. Lekarstvennyie sredstva. 16-e izdanie, pererab. i dopoln. Moskva : Novaya volna izdatel Umerenkov, 2010. 1216 p.

18. Gloriozova A., Filimonov D.A., Lagunin A.A., Poroykov V.V. Testirovanie kompyuternoy sistemyi dlya predskazaniya biologicheskoy aktivnosti PASS na vyibor kenovyih himicheskih soedineniy. Him.-farm. zhurnal. 1998. № 32. 12. P. 32-39.

19. Lagunin A., Stepanchikova A., Filimonov D., Poroikov V. PASS: prediction of activity spectra for biologically active substances. Bioinformatics. 2000. № 16.8. P. 747-748.

\section{Information about authors: Stadnytska N. Ye., Candidate of Chemical Sciences,} Associate Professor of Department of Technology of Biologically Active Substances, Pharmacy and Biotechnology Lviv Polytechnic National University 12, S. Bandera str., Lviv, 79013, Ukraine

Monka N. Ya.,

Candidate of Chemical Sciences, Assistant of Department of Technology of Biologically Active Substances, Pharmacy and Biotechnology Lviv Polytechnic National University 12, S. Bandera str., Lviv, 79013, Ukraine

\section{Lubenets V. I.,}

Doctor of Chemical Sciences, Professor, Professor of Department of Technology of Biologically Active Substances, Pharmacy and Biotechnology Lviv Polytechnic National University 12, S. Bandera str., Lviv, 79013, Ukraine 